\title{
Curso de Licenciatura em Matemática a Distância Uma Síntese do Projeto Pedagógico*
}

\author{
João Artur de Souza ${ }^{* *}$ \\ Elton Luiz Vergara Nunes ${ }^{* * *}$ \\ Gertrudes Aparecida Dandolini \\ Luiz Alberto Brettas
}

Resumo: A proliferação de ofertas de cursos a distância no Brasil, em nível de pósgraduação em instituições públicas e diversos cursos de graduação em instituições privadas, levou o Ministério da Educação a estabelecer regras para o credenciamento de instituições para a oferta de cursos a distância com diploma reconhecido. Este credenciamento não é dado genericamente à Instituição, mas com base na avaliação de oferta em cursos concretos na graduação. A UFPel recebeu seu credenciamento no final de 2004 com base no Projeto Pedagógico e oferta do Curso de Licenciatura em Matemática a Distância, cujo início está previsto para o segundo semestre letivo de 2005. Neste trabalho, apresentamos o Projeto deste Curso e suas peculiaridades. Trata-se de uma iniciativa de uma equipe de professores que aceitou o desafio imposto pela demanda social da região sul do Rio Grande do Sul, bem como da nova realidade da educação em nosso país e no mundo. A Universidade precisa assumir seu papel de facilitadora do acesso a conhecimento científico a todos, e buscar diferentes formas de alcançar esse propósito. O Curso de Licenciatura em Matemática a Distância é uma resposta dada para essa realidade.

Palavras-Chave: Ensino a Distância, Matemática, Projeto Pedagógico

Abstract: The increasing offer of e-learning courses in Brasil at graduate level in public institution and several undergraduate courses in private institutions, took the Ministry of Education of Brazil to establish rules to register institutions offering elearning courses with recognized diploma. This accreditation it is only given to the Institution, when based on a evaluation of the actual offer of the course. The Federal University of Pelotas has received its accreditation at the end of 2004 based on the Pedagogic Project of the e-learning mathematic course offered, that will start in the second semester of 2005. In this work we present the project of this course and its peculiarities. This project is an initiative of a group of teachers who have accepted the challenge imposed by the social demand of the southern region of Rio Grande do Sul. The University needs to play its role as facilitator to the access to scientific knowledge and to look for different forms of reaching that purpose. The e-learning course of mathematics is an answer to this reality.

Keywords: E-learning, Mathematic, Pedagogic projects

\footnotetext{
"Projeto financiado pelo SEED/MEC e FINEP.

** Professor, Licenciado em Matemática (UFSC) e Doutor em Engenharia de Produção na área de Inteligência Artificial (PPGEP/UFSC), Professor de Matemática e Coordenador do Curso de Matemática a Distância da UFPEL, jgartur@brturbo.com.br

*** Professor, Mestre em Educação (FAE/UFPEL), Professor de Letras/Espanhol da UFPEL, vergaranunes@gmail.com

**** Professora, Licenciada em Matemática (UFSC) e Doutora em Engenharia de Produção na área de Inteligência Artificial (PPGEP/UFSC), Professora de Matemática e Coordenadora do Curso de Matemática da UFPEL, ggtude@gmail.com

...** Professor, Bacharel em Matemática (UFRGS) e Doutor em Engenharia de Produção (UFSC), Professor de Matemática da UFPEL, labr@brturbo.com.br 


\section{Apresentação}

A Universidade Federal de Pelotas tem uma história bastante recente, porém muito rica, no tocante ao ensino a distância ${ }^{1}$ mediado por tecnologias, especialmente a informática.

Em 1997, após a homologação da Lei de Diretrizes e Bases (LDB) e o início das discussões pelas comissões de especialistas sobre as Diretrizes Curriculares para os cursos de graduação, começou-se a discutir a reformulação dos currículos dos cursos de graduação na UFPel. No ano de 2000, a UFPel ofereceu a professores e alunos uma série de encontros de discussão sobre diferentes aspectos relacionados com a tarefa de ensinar introduzindo o tema das tecnologias de comunicação e informação.

A partir dessas discussões, alguns professores e alunos seguiram mantendo contato e aprofundando seu trabalho em ensino mediado por tecnologias. A Administração Superior da UFPel investiu esforços na aquisição de equipamentos e instalação de salas e laboratórios com recursos de informática e de multimídias como suporte ao ensino. Entretanto, a produção oficial sobre ensino a distância não seguiu o mesmo ritmo, restringindo-se a iniciativas isoladas ou de pequenos grupos sem ter uma representatividade a ponto de criar uma presença forte dessa nova modalidade de trabalho.

No ano de 2001, uma equipe de professores da área de matemática aceitou o desafio imposto pela demanda social e assumido pela UFPel, como resposta a um novo momento da educação. Começaram os primeiros passos para a elaboração do Projeto Pedagógico do Curso de Licenciatura em Matemática a Distância (CLMD).

\section{Um pouco da história do ensino a distância}

Ao contrário do que muitos pensam, o Ensino a Distância não é uma novidade de nossos tempos, remonta às famosas Cartas de Platão e às Epístolas de São Paulo. Porém, sob o ponto de vista do ensino moderno, as primeiras iniciativas que se têm notícia remontam ao século XVIII com cursos preparados a partir de material impresso distribuído via postal (Gazeta de Boston -1728). No século XIX, ela teve seu reconhecimento na Europa e nos Estados Unidos, com autorização para concessão de diplomas de seus cursos. Já no século XX, filmes instrucionais foram elaborados na década de 20, mas logo caíram em desuso devido a sua baixa aceitabilidade, o que pode ser facilmente explicado pelas deficiências técnicas de então. As primeiras tentativas de transmissão de cursos via rádio também fracassaram nos Estados Unidos, devido, principalmente, à baixa qualidade dos cursos ofertados. Mas, tentativas semelhantes lograram êxito em países em desenvolvimento, como a Austrália, onde até hoje ocupam posição de destaque, e em alguns países do continente africano. Os primeiros cursos via televisão foram produzidos em 1934 pela Universidade de Iowa, nos Estados Unidos. Esses cursos tiveram sucesso imediato. Em dois anos, já haviam sido transmitidos mais de 400 cursos pela televisão da universidade. Em 1936 foi montada, em uma escola de Los Angeles, a primeira tele-sala, uma sala de aula para recepção de programas educacionais veiculados pela televisão. A partir da década de 70 esse sistema sofreu profundas modificações com a inserção de novos meios, como o jornal, a televisão e o computador. "No Brasil, desde a fundação do Instituto Rádio Monitor, em 1939, e,

\footnotetext{
${ }^{1}$ No curso de Matemática a Distância este texto optou-se pelo uso do termo "ensino a distância", embora se reconheça que não abarca toda a riqueza do processo educativo de um curso a distância. Termos como "educação a distância" e "aprendizagem a distância" foram preteridos por acreditar-se não representar adequadamente a realidade, já que, tanto a aprendizagem como a educação acontecem no próprio indivíduo, portanto, nunca a distância. 
depois, do Instituto Universal Brasileiro, em $1941^{2}$, várias experiências foram iniciadas e levadas a termo com relativo sucesso" (Guaranys e Castro, 1979, p.18). Na década de 70 aparecem o Projeto Minerva ${ }^{3}$, e o programa de educação supletiva a distância, para $1^{\circ}$ e $2^{\circ}$ graus da Fundação Roberto Marinho ${ }^{4}$. Em 1996, a UFSC implantou seu Programa de Educação a Distância Mediada por Computador ${ }^{5}$.

Modernamente, procura-se de alguma forma dotar os cursos a distância de interatividade. Pode-se até afirmar que a ausência da interatividade seja o principal fator de desestímulo à utilização desses cursos. Com o advento da internet, por suas facilidades, baixo custo e a massificação de seu uso, essa passou a ser o principal elemento para a interatividade, e até mesmo veículo de oferta de cursos a distância em todo o mundo. Segundo Machado (1999):

os recursos on-line permitem a emergência de comunidades virtuais de aprendizagem, caracterizadas por interações e convivências 'ao vivo' ou não, ausentes nas modalidades anteriores. De fato, através do rádio, da TV ou de fascículos impressos, o papel do emissor se limitava a orientar, de longe, o aprendiz, esperando e apostando num alto nível de motivação intrínseca, na autonomia e na disciplina para que ocorresse aprendizagem ${ }^{6}$.

O êxito de um curso a distância está diretamente relacionado com o seu planejamento, em todas as etapas, não dependendo da atuação, em separado, de um elemento, na cadeia processual, mas sim, dos princípios e parâmetros que norteiam o curso.

\section{Uma nova proposta pedagógica}

As novas condições da nossa sociedade, tanto em termos políticos, como em termos de tecnologia, cuja popularização cresce vertiginosamente, pressionam as IES a se remodelarem continuamente. No Brasil, as poucas iniciativas existentes na área de Ensino a Distância em Matemática encontram-se ainda em fase inicial de pesquisa e desenvolvimento, limitando bastante a oferta de programas em Ensino a Distância. A implantação deste sistema de educação beneficia grupos sociais que não são atingidos pelo sistema de educação clássica.

As dificuldades crônicas pelas quais passa o ensino de Matemática em nosso país têm início na escola básica, com reflexos acentuados no ensino superior. Este problema se acentua com a falta de alunos nos cursos de Licenciatura em Matemática e os altos índices de evasão desses cursos. A deficiência do ensino básico, em última instância, é devido ao despreparo, e em muitos casos, à falta de professores minimamente qualificados.

Nos levantamentos realizados pelo Instituto Nacional de Estudos e Pesquisas Educacionais (INEP), do Ministério da Educação, que vem obtendo informações sobre o desempenho dos alunos de nossas escolas desde 1991, por meio do Sistema Nacional de Avaliação da Educação Básica (SAEB), as deficiências de nossos alunos, em particular na área de Matemática, é comprovada e extremamente preocupante (Araújo e Luzio, 2003).

\footnotetext{
${ }^{2}<$ http://www.institutouniversal.g12.br/ > Acesso em 18 mar 2004.

${ }^{3}<$ http://www.eps.ufsc.br/disc/tecmc/bahia/grupo8/site/pag6.htm > Acesso em 15 fev 2004.

${ }^{4}<$ http://www.frm.org.br/ >

${ }^{5}<$ http://EaD.faesa.br/EaD.htm> Acesso em 19 mar 2004.

${ }^{6} \mathrm{~A}$ interatividade que se espera de um ambiente é aquela que leva à interação.

V. $3 \mathrm{~N}^{\circ} 1$, Maio, 2005
} 
No Sistema Nacional de Avaliação da Educação Básica/97 (SAEB/97), foi constatado que os alunos que disseram possuir microcomputador em casa obtiveram média muito superior aos que não tinham. Deve-se render à evidência de que os microcomputadores, aliados a sistemas de telefonia, oferecem novas formas de comunicação e facilidades de se obterem informações rapidamente e de forma extremamente ampliada, bem como as capacidades de manipulação de dados numéricos e visuais de maneira extremamente prodigiosa. Entretanto, esses dados ainda não são suficientes para concluir que o simples fato de ter acesso ao computador, em casa ou na escola, represente, necessariamente, uma melhora do desempenho dos alunos. Deve-se considerar, entre outros fatores, que esses alunos pertencem a classes sociais que estimulam seus filhos mais precocemente aos estudos.

Alguns críticos lembram do cuidado que se deve ter com relação a isso ao se referirem ao uso das novas tecnologias no ensino, afirmando que "não se deve ter a ilusão de que colocar computador na escola e treinar os professores em alguns cursos intensivos traduz-se numa melhoria da qualidade do ensino" (Cysneiros, 1998). É preciso repensar o modo de ensinar do professor, adequando-se as novas tecnologias à prática da escola - ensinar o aluno a aprender, explorando as ferramentas que estão ao seu alcance, para se ter uma melhoria acentuada da qualidade do aprender. A forma tradicional de aprendizado em um ambiente confinado como a escola, onde um professor em uma determinada data e hora passa as informações a um grupo de alunos em um determinado espaço físico vem sendo questionada há algum tempo (Romiszowsky, 1997) ${ }^{7}$.

Muitas experiências na utilização de tecnologias no ensino de graduação restringem-se à utilização de laboratórios de computação conectados em rede para a resolução de listas de exercícios, usando softwares, ou utilizam a rede como fonte de pesquisa via Internet, perpetuando o modelo tradicional linear de ensino, essencialmente baseado no conteúdo.

No ensino a distância, não somente mudam os métodos de trabalho, mas acima de tudo mudam as relações entre os sujeitos da educação e os princípios que dão base a essa nova prática. Conforme o professor José Manuel Morán ${ }^{8}$, especialista em tecnologias de comunicação aplicadas à educação, se não mudarem os princípios nesse novo ambiente de trabalho, as tecnologias poderão mascarar uma educação vertical, que ainda despreza o conhecimento que se constrói e o processo de formação do estudante (e do professor) como cidadão. É no ambiente virtual, com base numa pedagogia própria da internet ${ }^{9}$ (Vergara Nunes, 2002), que se vê de maneira mais concreta a idéia, defendida por Paulo Freire ${ }^{10}$, de diálogo entre os agentes do processo de aprendizagem, bem como o esvaziamento da ilusória posição de personagem central como detentor do conhecimento para o professor e o papel marginal imputado ao aluno, como aquele que nada sabe.

Um dos entraves para a implantação de projetos pedagógicos inovadores que utilizem os recursos da teleinformática para os cursos regulares e a implantação de programas de Ensino a Distância em Matemática e áreas afins, é a falta de recursos que a informática dispõe para a comunicação eletrônica Matemática. Os atuais sistemas informatizados que oferecem ambientes de comunicação (para utilização na web) ainda

\footnotetext{
${ }^{7}$ Mesmo no sistema presencial, essas questões também são levantadas, e a cada dia novas metodologias de trabalho são adotadas que valorizam as inteligências dos alunos e outros ambientes que ultrapassam as paredes da sala de aula.

${ }^{8}$ http://www.eca.usp.br/prof/moran/formas.htm, acesso em 27 de março de 2005

${ }^{9}$ Vergara Nunes explora esses aspectos que acabam sendo adotados por aqueles que usam a Rede, mesmo que não percebem. São pressupostos esperados pela Rede daqueles que dela fazem parte.

${ }^{10}$ Toda a obra de Paulo Freire pressupõe o diálogo como a melhor forma de educar. 
são bastante limitados com respeito ao tratamento de objetos matemáticos. Nesses sistemas, fórmulas são tratadas como se fossem figuras que o usuário não pode manipular. A interatividade desses sistemas restringe-se ao tratamento com o texto em termos de letras e símbolos da escrita comum e não ao tratamento de representações simbólicas e gráficas em termos de conceitos matemáticos. Neste sentido, o desenvolvimento de novos softwares, ou a modificação de softwares já existentes, podem fazer com que seja alcançado um nível adequado de interatividade, ao se tratar com matemática, nos sistemas de comunicação baseados na web ${ }^{11}$.

As tecnologias de informação e os recursos da teleinformática podem propiciar a criação de ambientes para cursos a distância de qualidade, motivadores, atrativos, interativos, cooperativos, de comunicação síncrona e assíncrona rápida e de baixo custo. Esses elementos são fundamentais, porém a interação é o elemento básico.

A construção de um ambiente para a aprendizagem de Matemática a distância ${ }^{12}$ deve estar baseado numa mudança de paradigma (Morán, 2004) de "diretivo/linear" para o "interativo/construtivo". Este é um fenômeno emergente que se encontra num estágio de pesquisa e desenvolvimento em todo o mundo tanto por empresas como instituições de pesquisas.

Nesta perspectiva, de um novo paradigma de Ensino, é que o projeto do Curso de Licenciatura em Matemática a Distância se lança.

\section{Projeto pedagógico do curso}

O Curso de Licenciatura em Matemática a Distância da UFPel visa a formar professores de Matemática com conhecimentos, habilidades e atitudes condizentes com um profissional capacitado para atuar na segunda fase do Ensino Fundamental e no Ensino Médio e preparado para continuidade de estudos em nível de Pós-graduação em Educação, em Matemática ou em áreas afins. parâmetros:

O modelo que se pretende implementar na UFPel baseia-se nos seguintes

- Sólida formação teórico-prática;

- Nova relação entre professor-aluno;

- Interação entre os sujeitos;

- Interatividade aluno-ambiente de aprendizagem;

- Formação de um professor-pesquisador;

- Aprendizado autônomo (individual e cooperativo);

- Utilização de meios e recursos técnicos;

- Comunicação multidirecional.

O curso visa a oferecer aos seus egressos uma sólida formação de conteúdos matemáticos, formação pedagógica dirigida ao trabalho de professor, desenvolvimento de conteúdos de áreas afins e uma formação que possibilite a vivência crítica da realidade do ensino, necessárias ao exercício do magistério, tornando-os capazes de experimentar propostas interdisciplinares com seus alunos.

\footnotetext{
${ }^{11}$ A existência de softwares especializados para matemática revela uma preocupação existente com a área. No site http://www.somatematica.com.br/ existe uma área restrita (para cadastrados) onde são disponibilizadas dezenas de softwares.

12Experiências em ensino de matemática a distância podem ser encontradas em http://www.cederj.edu.br/cederj/matematica/funciona.php, http://www.dEaD.ufpa.br/internas/cursomat.html.

V. $3 \mathrm{~N}^{\circ} 1$, Maio, 2005
} 
Para isso, este curso se utilizará como princípio educativo, da articulação entre teoria e prática, do planejamento de ações pedagógicas e tecnológicas, considerando as necessidades de aprendizagem e o perfil cultural dos alunos, dentro da perspectiva que entende o estudante construindo seu próprio conhecimento. Nessa nova perspectiva, mudam conceitos como de freqüência, de tempo e espaço, de responsabilidade, de motivação e cobrança, de professor e aluno, de poder e compromisso coletivo.

De acordo com as tendências atuais dos cursos de formação de professores, o currículo do Curso de Licenciatura em Matemática a Distância será composto por um módulo obrigatório e outro complementar que atenderá às especificidades de cada aluno.

O currículo será composto por quatro conjuntos de atividades acadêmicas: um conjunto de disciplinas formadoras, um de disciplinas pedagógicas e um de disciplinas integradoras e as atividades complementares.

\section{Objetivos do Curso}

O CLMD assume o compromisso de aumentar a participação da UFPel no desenvolvimento da educação em Matemática. Desta forma pretende atingir populações que vivem em regiões afastadas dos grandes centros e contribuir para o desenvolvimento dos municípios que serão atingidos por este projeto, denominados pólos. Com a implantação do Curso nesses pólos, a Universidade passa a promover o ensino de Matemática também nos níveis Fundamental e Médio nessas cidades e região.

Mais do que o desenvolvimento genérico do ensino de matemática, o projeto visa a possibilitar a formação de um maior número de novos docentes na área de Matemática, contribuindo, dessa forma, para a transformação da atual situação do ensino e da aprendizagem de Matemática do Ensino Básico. Além disso, quer-se possibilitar a educação continuada aos professores que já atuam nas escolas sem ter a formação adequada e promover a atualização dos professores que já possuem formação.

Do ponto de vista metodológico, busca-se formar uma nova mentalidade com relação às tecnologias e às formas de aprender e desenvolver um ensino colaborativo dentro de um processo cooperativo de aprendizagem. Desenvolve-se no professor do Ensino Básico a competência para usar os meios de comunicação para sua educação continuada e para enriquecer a aprendizagem de seu aluno.

\section{Proposta Pedagógica}

Para formar profissionais competentes dentro dessa proposta pedagógica, o curso deve desenvolver nos seus alunos um pensamento heurístico competente: capacidade de encaminhar solução de problemas e explorar situações, fazer relações, conjeturar, argumentar e avaliar; capacidade de formular problemas; capacidade de leitura e redação. O curso se utilizará, como princípio educativo, da articulação entre teoria e prática, do planejamento de ações pedagógicas e tecnológicas, considerando as necessidades de aprendizagem e o perfil cultural dos alunos, dentro da perspectiva que entende o estudante construindo seu próprio conhecimento.

Esse professor deve ser seguro de si em seu trabalho, deve ter consciência de que é o responsável pelo seu trabalho e que sua formação o habilita como educador. Além dessas orientações em termos de competências e de sua segurança como profissional ${ }^{13}$,

\footnotetext{
${ }^{13}$ Em seu livro Pedagogia da Autonomia, Paulo Freire (1999) adverte sobre a importância de que o professor seja não somente capaz de relacionar-se humanamente com o aluno e o mundo, mas que seja competente tecnicamente, que domine os conteúdos próprios de sua área. 
entende-se, também, que o mesmo deve se portar criticamente frente a situações com as quais se deparar, tanto diretamente em seu trabalho nas escolas quanto fora delas.

Com os crescentes avanços tecnológicos, novas formas e possibilidades de se desenvolver o processo de ensino-aprendizagem tornam-se viáveis. Estes avanços, principalmente nas formas de comunicação e armazenamento da informação, é que tornam possível a promoção do ensino a distância. As mais variadas mídias podem ser colocadas à disposição para promover uma interação, um tanto quanto natural, entre os usuários de sistemas que buscam o processo de ensino aprendizagem. A evolução que as tecnologias de comunicação e interação sofrem é suficiente para que as possamos inserir no processo educativo.

A educação a distância busca uma relação entre aluno e professor, entre aluno e aluno, ou seja, entre pessoas que querem aprender e pessoas que estão dispostas a ajudar nesse processo. Trata-se de um processo complexo e que depende, principalmente, do quanto os envolvidos estão comprometidos e entusiasmados com o que pode acontecer. A liberdade de buscar novos conhecimentos, ou seja, a autonomia de trabalho, deve ser uma prática constante nesta proposta de licenciatura e um objetivo a ser incentivado.

As principais vantagens de um trabalho apoiado no Ensino a Distância residem no fato de que o ambiente amigável permite que:

- os cursos criados possuam grande capacidade de interatividade, possibilitando uma participação intensa do aluno no processo de aprendizagem;

- o autor do curso não precisa ser necessariamente um especialista em Internet;

- a reutilização de conteúdos e recursos existentes em mídia digital.

O material didático e o corpo docente devem oferecer, ao discente, orientações que o motivem e possibilitem construir, por si mesmo, em atividades individuais e, em grupo, os conhecimentos necessários para sua formação. Esses conhecimentos devem fornecer, ao licenciando, subsídios suficientes para que o mesmo tenha condições de tratar, com competência, de suas responsabilidades como docente no futuro.

\section{Execução das Aulas}

Serão utilizados os diversos meios disponíveis de comunicação e processamento geral de informações, ambiente web para educação virtual, páginas com conteúdos por disciplinas, correio eletrônico e outros ambientes virtuais. Serão enviados materiais impressos, fitas de vídeo, CDs e DVDs interativos como materiais de suporte para cada um dos pólos. Em todos os blocos semestrais ocorrerão momentos presenciais. Os momentos presenciais com os professores responsáveis dar-se-ão no início e final de cada bloco. Algumas disciplinas específicas (como as disciplinas de Prática de Ensino) terão um número maior de momentos presenciais. A tutoria se dará também em momentos presenciais, com encontros com os alunos nos pólos, além do acompanhamento pelos professores responsáveis via web. Os alunos contarão também com a assessoria de monitores presencialmente nos pólos e do Laboratório de Ensino de Matemática a Distância através da web.

De uma forma geral, o curso terá uma distribuição de momentos presenciais e não presenciais, promovendo a interação como forma e meio principal para o desenvolvimento da aprendizagem. O aluno, ao se matricular, deverá receber um Guia Geral, que conterá explicações sobre a execução do curso. Este Guia oferecerá orientação ao aluno sobre seus direitos e obrigações e as responsabilidades das pessoas envolvidas no curso. 
No início de cada bloco semestral, os alunos receberão o Guia de Atividade (GA) que objetiva definir as particularidades de cada bloco e de cada disciplina para sua execução. Contém os planos de ensino, cronograma de atividades (datas e horários dos encontros presenciais, datas das avaliações e momentos de comunicação síncrona), indicação dos materiais impressos a serem utilizados e das páginas das disciplinas, indicação dos vídeos, exercícios de auto-avaliação, bibliografia, sugestões para complemento ou aprofundamento, entre outros assuntos relacionados às disciplinas.

A partir do primeiro encontro iniciam os trabalhos de orientação por disciplina pelo grupo responsável por ela. Cada tutor e monitor terão os encontros presenciais com os seus alunos proporcionais à carga horária da disciplina ${ }^{14}$. Quanto à monitoria, sua presença nos laboratórios dos pólos terá horários fixos que facilitem aos alunos os acessos aos equipamentos e orientações sobre os conteúdos das disciplinas do bloco. Estas informações farão parte do guia de atividades, bem como informações gerais sobre o bloco. O guia terá capítulos específicos para cada disciplina do mesmo.

Os alunos terão um treinamento inicial com os meios necessários para o acompanhamento do curso, para romper a tecnofobia e se familiarizarem com o novo sistema de ensino. Participarão deste treinamento os professores, tutores, técnicos e monitores. Deve-se levar em consideração a necessidade de aprender não somente o domínio dos recursos informáticos e manuseio de tecnologias diversas, mas especialmente a mudança de mentalidade e de paradigmas de educação. Ao entrar nessa nova modalidade de ensino, os sujeitos devem assumir novas posturas em relação ao seu papel. Não basta ensinar ou aprender, mas perceber sua responsabilidade na construção dos novos conhecimentos. Os conteúdos não são os únicos conhecimentos construídos, mas especialmente as estratégias de aprendizagem, que servem de base e recursos para outras aprendizagens menos específicas ao curso.

A interação entre o professor (seja o professor responsável ou o tutor) e aluno é fundamental em um curso dessa natureza. Ela se dará através de Ambientes Virtuais de Interações Verbais - AVIV (síncrona), através de correio eletrônico e murais virtuais (assíncrona) e encontros presenciais em cada um dos pólos, além de comunicação via telefone. Os AVIV representarão os momentos de "contato" a distância entre professoraluno e aluno-aluno, estabelecendo-se debates entre as partes envolvidas, dando dinâmica ao curso. O correio eletrônico e os murais virtuais representam elementos imprescindíveis aos modernos cursos a distância. Eles estabelecem canais permanentes entre o professor e o aluno e os alunos entre si.

O aluno terá à sua disposição um laboratório com computadores em rede com acesso à Internet. Esses laboratórios estarão presentes em cada um dos pólos a fim de atender aos alunos e um laboratório na sede do Curso (UFPel) para possíveis aulas presenciais e para os professores elaborarem e manterem os conteúdos das disciplinas, bem como para se comunicarem com os alunos (através de correio eletrônico e conversas em salas virtuais).

Todo o desenvolvimento do curso será executado em blocos semestrais, com avaliações constantes do trabalho didático-pedagógico dos alunos e acompanhamento de experiências de ensino em escolas da região onde o estudante reside ou trabalha, conforme o programa da disciplina.

Parte dos procedimentos didáticos das disciplinas do Curso envolve o envio de conjuntos de materiais ou de orientações para que os alunos possam consegui-los em suas próprias cidades para realização de experiências. Essas experiências devem propiciar-lhes a construção de seu próprio conhecimento matemático e de outras áreas importantes para sua formação como licenciados.

${ }^{14}$ A distribuição de horários por disciplina constará no Guia de Atividades do bloco. 
O ambiente virtual (plataforma) que o Curso de Licenciatura em Matemática a Distância da UFPel utilizará é imprescindível. Qualquer plataforma que não contemple a facilidade de comunicação síncrona utilizando elementos simbólicos e de estruturas de matemática seria por demais restritiva à concepção de $\mathrm{EaD}$ que norteia nosso curso. $\mathrm{O}$ ambiente AMADIS $^{15}$ (Ambiente de Aprendizagem a Distância) atenderá gradativamente essa necessidade, com adaptações oriundas da necessidade do Curso.

Juntamente com início do Curso, também iniciarão diversos projetos já aprovados institucionalmente, entre eles, o banco de imagens e vídeos, Biblioteca Virtual de Matemática ${ }^{16}$ e o sistema de reconhecimento de padrões para obtenção de perfis. O curso está preparando a elaboração de sites não atrelados a disciplinas específicas ou qualquer atividade acadêmica, mas que estarão à disposição dos alunos para os momentos de lazer de descontração.

\section{Material Didático}

O material didático do curso utilizará diversas mídias, dentre as quais podemos destacar: material impresso; hipertextos; vídeos; áudios; material concreto para os laboratórios; ambiente web específico; biblioteca virtual; entre outros.

$\mathrm{O}$ uso de materiais do tipo impresso não será a alternativa barata e menos trabalhosa para o uso neste Curso. Está prevista a confecção de livros para as disciplinas, que conterão não somente o conteúdo da disciplina, mas, também, exercícios e orientações para os alunos. Entretanto, diversos outros materiais deverão ser adotados em todas as disciplinas. Essa diversidade busca motivar o aluno a se tornar mais autônomo, dando-lhe diferentes possibilidades de avançar em suas descobertas e buscar suas próprias respostas para a aprendizagem do conteúdo trabalhado.

Cada pólo será dotado de uma biblioteca física, com livros e de um laboratório de ensino de matemática com material concreto a ser utilizado pelos alunos em aulas experimentais de matemática.

Todo o gerenciamento do material didático a ser utilizado no curso terá uma préaprovação do Laboratório de Ensino de Matemática a Distancia (LEMAD), cujas especificações estão na seqüência.

\section{Laboratório de Ensino de Matemática a Distância}

O Laboratório de Ensino de Matemática a Distância é peça fundamental para que os objetivos do projeto do Curso sejam alcançados. Não se trata de mera oficina de produção de materiais didáticos, ou núcleo informático de cunho educacional. Trata-se de um espaço de discussão e pesquisa em educação que visa à melhoria da qualidade não somente do curso que é oferecido aos alunos, mas do trabalho docente dos professores e tutores envolvidos no Projeto.

Um laboratório de ensino a distância é essencialmente multidisciplinar rompendo barreiras até pouco tempo intransponíveis. O rompimento de pré-conceitos que encerravam campos do saber em gaiolas transforma-se em desafios. Revela-se tal propósito com a adoção de uma sólida base teórica no campo do ensino a distância com o conhecimento da matéria a ser ensinada e da metodologia a ser utilizada. Nem só

\footnotetext{
${ }^{15}$ Desenvolvimento no Laboratório de Estudos Cognitivos (LEC) da Universidade Federal do Rio Grande do Sul.

${ }^{16} \mathrm{Em} \mathrm{http://www.ufpel.edu.br/bvl/} \mathrm{está} \mathrm{a} \mathrm{Biblioteca} \mathrm{Virtual} \mathrm{de} \mathrm{Letras,} \mathrm{do} \mathrm{grupo} \mathrm{de} \mathrm{pesquisa} \mathrm{Biblioteca} \mathrm{Virtual,} \mathrm{do} \mathrm{CNPq,}$ que servirá como base para a Biblioteca Virtual de Matemática. Para a Biblioteca de Matemática será aproveitada toda a estrutura do atual banco de dados e princípios de busca e inserção de obras. O sistema precisará sofrer alterações em sua programação, a fim de permitir a inclusão de obras de matemática, numa área nova no banco, bem como a definição de um design que designe a nova área da Biblioteca Virtual.

V. $3 \mathrm{~N}^{\circ} 1$, Maio, 2005
} 
conteúdo nem só o meio, mas uma produção conjunta entre professores, técnicos, estudiosos das tecnologias e da pedagogia dos ambientes virtuais. Basicamente a equipe está composta por técnicos em programação informática e designers, que trabalham com orientação pedagógica do coordenador do Laboratório, além dos professores responsáveis pelas disciplinas. Dentro do Projeto ainda está prevista a colaboração do trabalho de profissionais ligados à área de comunicação, letras, psicologia, sociologia e todas aquelas que se fizerem necessárias para a melhoria da qualidade do curso.

\section{Conclusão}

Nossa proposta, longe de se tratar de mero modernismo por tecnologias, representa uma alternativa viável para atendimento de uma demanda social que, do modo tradicional de ensino presencial, foge às condições financeiras de infra-estrutura e de pessoal da Universidade, o que não permite uma resposta condizente com a necessidade identificada na região. Com esse modelo proposto, otimiza-se a competência instalada na UFPel, de forma a atender, principalmente, as necessidades de formação de professores de Matemática.

\section{Referências Bibliográficas}

ARAÚJO,C. H. E LUZIO, N. W. SAEB e Eqüidade. SAEB: inclusão pela qualidade. Disponível em < http://www.tvebrasil.com.br/salto/boletins2003/saeb/tetxt3.htm >. Acesso em: 28 mar 2005.

CYSNEIROS, P.G. Novas Tecnologias na sala de aula: melhoria do ensino ou inovação conservadora. IX ENDIPE - Encontro Nacional da Didática e Prática do Ensino, Águas de Lindóia, SP. Anais II, vol.1/1, pp. 199-216, 1998.

FREIRE, Paulo. Pedagogia da Autonomia. São Paulo: Editora Paz e Terra, 1997.

GUARANYS, L.R. dos. CASTRO, C.M. O ensino por correspondência: uma estratégia de desenvolvimento educacional no Brasil. Brasília: IPEA, 1979.

MACHADO, E. EAD - Algo mais Amplo que Ensino a Distância. Texto 85, lista de Discussão - "Desafios Educacionais" Coordenação: Conselho de Educação do Ceará Disponível em < http://www.cec.ce.gov.br > . Acesso em: 28 nov 1999.

MORÁN, J. M. Mudar a forma de ensinar e de aprender com tecnologias - transformar as aulas em pesquisa e comunicação presencial-virtual. Disponível em <http://www.eca.usp.br/prof/moran/uber.htm>. Acesso em: 10 abr 2004.

ROMISZOWSKY, A.,J. Web-Based Distance Learning and Teaching: Revolutionary Invention or Reaction to Necessity? Web-based instruction, pp 25-37, Educational Technology Publications, New Jersey, 1997.

VERGARA NUNES, Elton L. Pedagogia da internet. Pelotas: FAE/UFPel, 2002, Dissertação de Mestrado. 